\title{
Poultry meat quality and welfare as affected by organic production system
}

\author{
Talha ELsadig Abbas, Mohamed Elamin Ahmed \\ Department of Animal Production, University of ALneelain, Khartoum, Sudan \\ Email address \\ talhabbs@yahoo.com (T. E. Abbas),moha_555@hotmail.com (M. E. Ahmed)
}

\section{To cite this article:}

Talha ELsadig Abbas, Mohamed Elamin Ahmed. Poultry Meat Quality and Welfare as Affected by Organic Production System. Animal and Veterinary Sciences. Special Issue: Poultry Welfare: Housing Systems and Feeding. Vol. 3, No. 5-1, 2015, pp. 1-4.

doi: 10.11648/j.avs.s.2015030501.11

\begin{abstract}
Most of consumers preferring organic food accompanied emerge of environmental awareness in the last decades. Organic production system is considered as an important solution for the environment problems because it improves sustainable agriculture by using organic compounds and avoiding synthetic chemical ones, restricting intensive production and making the entire chain of production under control. Therefore, it is encouraged and supported by environmental protection agencies in spite of the higher production cost of organic production compounds. Due to its higher production cost most producers prefer intensive systems because they focus on reducing cost and increasing production regardless of environmental degradation. Organic poultry system usually mentioned with free-range system and poultry welfare. That is because all organic systems are free-range. Organic system gets a lot of attention of animal welfare organizations because it assists birds to express normal behavior by offering plenty space. Organic or free-range system by some modifications and developing of the system regarding good management of its environment in addition to establishment of biosecurity measures it could considered as a suitable system for human, poultry and environment rather than intensive system because it achieves human health by avoiding dangerous remainders in food such as chemical residues, and for poultry by offering good welfare and health, and also to environment by improving sustainable agriculture.
\end{abstract}

Keywords: Free-Range, Organic system, Poultry, Sustainable Agriculture, Welfare

\section{Introduction}

Increasing demand for livestock products leads to rapid growth of livestock production systems. This increase in demand occurred due to population growth, urbanization and increasing income in developing countries. In developed countries increase in production and consumption of livestock products is going slowly because they reached their higher levels [1]. Livestock production systems either produce positive or negative effects on natural resources, public health, social equity and economic growth [1]. Due to expected negative effects of livestock production systems on the environment and natural resources especially when production is left entirely to the market without policy and regulations to control production process, organizations that considering some aspects such as environment protection and animal welfare were appeared mainly in Europe and United States, and this encourages emerge of consumers preferring organic food. Organic production system is defined within the European Union as the system of agriculture that aims to promote sustainable agricultural development. Its objectives are to produce products without chemical residues i.e. avoiding the use of artificial chemical pesticides, fertilizers and antibiotics and applying techniques prevent soil degradation [2]. In the last decades increase of organic farming was observed around the world especially in Europe and United States. In Europe, organic area increased by about 500000 hectares per year in the last decade, and according to Eurostat data, the EU 27 about 9.6 million hectares are managed organically in 2011 comparing to 5.7 million hectares in 2002 [3]. In United States, after National Organic Program (NOP) performed by United States Department of Agriculture (USDA) in 2002 the development of organic market has increased strongly, especially poultry products [4].

The aim of this review is to exhibit progress of organic poultry systems and its differences from free-range system and its effects on poultry performance and meat quality in addition to its role in supporting animal welfare. 


\section{Organic Poultry Production}

It is a kind of poultry management that allows birds to express natural behavior such as pecking, scratching, foraging and exercise outdoors, and diseases control achieved without antibiotics or other drugs (except vaccination). Regarding nutrition only organic feed is used preferably local feed ingredients. It is the feed that produced without synthetic fertilizers and pesticides [4]. The origin of birds used in organic systems, according to NOP, it is not necessary to be organic. Nonorganic chicks (day posthatching) can be used but they should be managed organically after the second day post-hatching. High-yielding breeds are used in the United States in both conventional and organic systems. These breeds may suffer from health problems due to higher production such as metabolic problems and sudden death syndrome in addition to leg problems and brittle bones (osteoporosis) which strongly depends on nutrition particularly calcium and available phosphorous as well as vitamin D supply. Therefore in European Organic Systems slow-growing birds are used for meat production and heritage breeds for egg production [5]. In organic system birds should managed as land-based system that means avoiding intensively-housed units and herd numbers depend on the carrying capacity of the land [6]. In some researches we find free-range system described as organic system, even some consumers confuse between them [7], but they are different. All organic systems are free-range systems because one of the standards of organic system is allowance for natural behavior expression with outdoor access [5]. But not all free-range systems are organic systems because in addition to outdoor access the system should achieve standards such as avoiding use of chemicals like antibiotics and use only organic feed which produced without chemicals fertilizers and pesticides so as to accept as organic system [4]. Example of free-range systems that is not organic system is the activity of raising poultry practiced in the tropics. Production of small flocks of chickens in free-range system is the agricultural activities of approximately all rural and peri-urban families in developing countries [8]. Despite of flourishing of free-range system in developing countries its role in improving rural economics is low due to low level of production and absence of good management [9]. Inability of rural families to improve their poultry production and subsequently, achieve organic standards is mainly due to deficiency in husbandry skills and training [10]. Organic poultry production in developing countries as in Nigeria has not gained attention as in developed countries. Although, some traditional veterinary medicine are practiced in rural poultry farming which is look like some sort of organic activities, but these cannot considered as organic system because the lack of scientific and professional methodology [11]. Therefore, to make free-range system active in improving rural economics in developing countries scientific researches regarding free-range and organic systems should be supported and financed by organizations and working groups. Also, governments of these countries should take their role of encouraging poultry production to get up with this system. Furthermore, enhancing small-holders skills by education and performing training courses considering poultry management [12].

Effects of Organic System on Poultry Performance and Meat Quality

Pasture grazing decreases lipid content of poultry meat and enhances performance and meat sensory, beside increases polyunsaturated fatty acids and n-3 polyunsaturated fatty acids in breast meat [13], thigh [14] and breast meat and drum stick [15] and this compound is important to decrease occurrence of cardiovascular diseases in human [16]. According to [15] raising broilers in free-range system resulted in higher percentage of breast and thigh muscles. Broilers kept in free-range system exhibited significantly higher protein and lower fat contents of white and dark meat [17]. On the other hand, chickens raised with outdoor access showed increased feed consumption and poorer feed efficiency [18]. Authors examined slow-growing and fastgrowing chicken genotypes. Disagree with these findings [19] failed to obtain effects of outdoor access on the performance and carcass yields when slow-growing and fast-growing chickens were used. Absence of the effect on the carcass yields and meat quality has been reported in addition to reduction in body weight and weight gain when slowgrowing chickens were reared in free-range system [20]. These results agreed with those obtained by [21]. Authors attributed lower body weight and weight gain that observed when slow-growing chickens reared in free-range system to exposure to fluctuating temperature and more activities which lead to increase energy requirements.

\section{Welfare}

Welfare is example of those words (health, pleasant feelings, freedom ... etc.) that often represent a kind of vague concept [22]. Therefore there is a debate between scientists about description of welfare. Welfare bases on feelings of birds and the balance of quality throughout life has been explained by [22]. In that opinion author is agreeing [23]. The author mentioned that empirical study of animal welfare depends on detecting uncomfortable feelings such as fear, boredom, pain and hunger rather than response of birds to the environment. Other scientists exhibited different opinion about definition of welfare. Animal welfare involves opportunity to express natural behavior and absence of injuries and pain besides well health and physiology [24]. Involvement of comfort behavior and well health as a description of animal welfare also, declared by [25]. According to Farm Animal Welfare Committee (FAWC) five standards should be accomplished to consider animal welfare 1- Freedom from hunger and thirst, by providing accessible fresh water and diet. 2- Freedom from discomfort, by supplying suitable environment. 3- Freedom from pain, injury and disease by prevention or prompt diagnosis and treatment. 4- Freedom to express normal behavior by offering plenty space and convenient facilities. 5- Freedom from fear 
and distress, by providing proper conditions and treatment to prevent mental suffering [26].

\section{Organic Production System and Poultry Welfare}

In spite of spread of organic animal products there are limited researches considering animal health and welfare in this system [27]. According to the available literature situation of welfare in organic system needs more investigation. This is because various perceptions of actual meaning of welfare. In spite of the importance of welfare as one of the objectives of organic system farmers mainly concentrated on sustainability rather than welfare [28]. There is an absence of major discrepancy among farmers, IFOAM ${ }^{1}$ and consumers but their perceptions about practice that is important for welfare are differ [29]. Most of health and welfare issues of conventional free-range system such as cannibalism, feather pecking, predators, coccidiosis and bacterial infection can be seen in organic system [28]. The author attributed this to insufficiency of basic information about biosecurity, disease detection and disease prevention that obtained by organic farmers. Furthermore, in free-range system there is possibility of getting unbalance feed [30]. Therefore, organic animal production doesn't always mean good health and welfare [31]. It was reported that, the cause that inhibited development of organic animal production is the absence of obligations and instructions that guide human to deal friendly with animals [29]. On the other hand, some researchers declared that animal welfare is better in organic system than in conventional system except for parasites infestation [28]. Also, some consumers agree with this opinion, therefore they buy organic food [7]. Consumers buy organic food because they think organic farms achieved animal welfare standards, but animal welfare is not a priority in buying food [32]. Reduction of occurrence of feather pecking in free-range system has been declared by [33, 34]. This attributed to the lower stocking density of the system [35].

\subsection{Suggestions to Achieve Welfare in Organic Production System}

One of the health problems that faced birds raised in freerange system is their contact to wild birds, especially ducks, which leads to transmission of infectious diseases to domestic poultry [36]. Most of these contacts occur during outdoors access. Therefore, it is better to avoid occurrence of this contact during migrating season to reduce risk of diseases transmission. This can be achieved by developing the system with guidance of official veterinary services [37] and by establishment of biosecurity measures [23]. Another health problem observed in free-range system is the feather pecking. Genetic selection of birds that have a lower

${ }^{1}$ IFOAM (International Federation of Organic Agricultural Movements): The IFOAM's Basic Standards are the most widely used organic standards worldwide. propensity for injurious feather pecking has been suggested to reduce the risk of feather pecking. Parasitic infestation is considered as one of the important problems observed in free-range system. To reduce risk of parasitic diseases changing pasture areas has been recommended and using new clean pasture for each batch [38]. Coccidiosis considered as one of the major problem in organic system. Vaccination has been suggested as a useful practice instead of supplementation of coccidiostats to the diet [6]. Regarding higher mortality rate due to predators in free-range housing, work by [39] has shown range enrichment (trees or tall grass stand) reduces mortality rate. Otherwise electric fence can be used to keep predators faraway [6].

\section{Conclusion}

It was concluded that, in spite of insufficiency of organic system to accomplish higher standard of animal welfare in addition to its inconclusive effect on growth performance it supports human health, poultry welfare and environment maintenance compared to intensive system which mainly concentrated on higher income. Life is based on equilibrium of aims achievement rather than concentration on one target. There is common agreement that priority in life should be directed towards human health and safety then animal welfare and environment maintenance. Therefore organic production system should get more consideration and researches to achieve maximum expected profits.

\section{References}

[1] World Bank. Minding the stock: Bringing public policy to bear on livestock sector development. Report No. 44010-GLB. Washington DC. 2009.

[2] Stolze M, Piorr A, Häring A, Dabbert S. Organic Farming in Europe: Economics and Policy. University of Hohenheim/Department of Farm Economics, Stuttgart, Germany.2000; 15-22.

[3] European Commission. Facts and figures on organic agriculture in the European Union. Agriculture and Rural Development, European Union. http://ec.europa.eu/agriculture/rural-areaeconomics/index_en.htm. 2013; 5-6.

[4] Fanatico AC, Owens CM, Emmert JL. Organic poultry production in the United States: Broilers ${ }^{1}$. J Appl Poult Res. 2009; 18: 355-366.

[5] Fanatico A. Organic poultry production in the United States. National Center for Appropriate Technology (NCAT). ATTRA www.attra.ncat.org/attra-pub/PDF/organicpoultry.pdf. 2008.

[6] Lampkin N. Organic poultry production. Final report to MAFF Welsh Institute of Rural Studies. University of Wales. Aberystwyth. 1997; 3-16.

[7] Harper GC, Makatouni A. Consumer perception of organic food production farm animal welfare. Bri Food J. 2002; 104: 287-299. 
[8] Jens Christian R, Anders B, Charlotte V, Ainsh MC, Lone, F. Keeping village poultry. A technical manual for small-scale poultry production. Copenhagen, Denmark. 2004.

[9] Shumba EM, Whingwiri EE. Prospects for increased livestock production in communal areas: An agronomist perspective. In: Research and Extension for Livestock in Communal Area Farming Systems. Henderson Research Station. Mazoe. Zimbabwe. 10-18 February. 1988

[10] Mlozi MRS, Kalengi AVM, Minga UM, Mtambo AM, Olsen JE. Marketing of free-range local chickens in Morogoro and Kilosa urban markets, Tanzania. Livest Res Rural Dev. 2003; Vol. 15, Article 2 http://www.lrrd.org/lrrd15/2/mloz152.htm.

[11] Adedeji OS, Ogunsina TK, Akinwumi AO, Ameen SA, Ojebiyi OO, Akinlade JA. Potential challenges to the adoption of organic poultry farming in Nigeria: A review. Iran J Appl Anim Sci. 2013; 3: 653-656.

[12] Abbas TE. Poultry welfare in developed and developing countries. Anim Vet Sci. 2014; 2: 1-4.

[13] Ponte PIP, Prates JAM, Crespo JP, Crespo DG, Mourão JL, Alves SP, Bessa RJB, Chaveiro-Soares MA, Gama LT, Ferreira LMA, Fontes CMGA. Restricting the intake of a cereal-based feed in free-range-pastured poultry: Effects on performance and meat quality. Poult Sci. 2008; 87: 2032-2042.

[14] Chen X, Jiang W, Tan HZ, Xu GF, Zhang XB, Wei S, Wang $\mathrm{XQ}$. Effects of outdoor access on growth performance, carcass composition and meat characteristics of broiler chickens ${ }^{1}$. Poult Sci. 2013; 92: 435-443.

[15] Castellini C, Mugnai C, Dal Bosco A. Effect of organic production system on broiler carcass and meat Quality. Meat Sci. 2002; 60: 219-225.

[16] Betti M, Perez TI, Zuidhof MJ, Renema RA. Omega-3enriched broiler meat: 3. Fatty acid distribution between triacylglycerol and phospholipid classes. Poult Sci. 2009; 88: 1740-1754.

[17] Bogosavljevic-Boskovic S, Mitrovic S, Djokovic R, Doskovic V, Djermanovic V. Chemical composition of chicken meat produced in extensive indoor and free range rearing systems. Afr J Biotechnol. 2010; 27: 9069-9075.

[18] Fanatico AC, Pillai PB, Hester PY, Falcone C, Mench JA, Owens CM, Emmert JL. Performance, livability and carcass yield of slow- and fast-growing chicken genotype fed lownutrient or standard diets and raised indoors or with outdoor access. Poult Sci. 2008; 87: 1012-1021.

[19] Mikulski D, Celej J, Jankowski J, Majewska T, Mikulska M. Growth performance, carcass traits and meat quality of slower-growing and fast-growing chickens raised with and without outdoor access. Asian-Aust J Anim Sci. 2011; 24: 1407-1416.

[20] Wang KH, Shi SR, Dou TC, Sun HJ. Effect of free-range raising system on growth performance, carcass yield and meat quality of slow-growing chicken. Poult Sci.2009; 88: 22192223.

[21] Dou TC, Shi SR, Sun HJ, Wang KH. Growth rate, carcass traits and meat quality of slow-growing chicken grown according to three raising systems. Anim Sci Pap Rep. 2009; 27: 361-369.
[22] Kirkwood JK. The importance of welfare. In: Welfare of the Laying Hen: Poultry Science Symposium Series. Vol. 27. (ed. Perry GC) CABI Publishing. CAB International. 2004; 1-7.

[23] Dawkins MS. From an animal's point of view: Motivation, fitness and animal welfare. Behav Brain Sci. 1990; 13: 1-9 (Abstract).

[24] EFSA. The welfare aspects of various systems of keeping laying hens. EFSA J. 2005 ; 197: 1-23.

[25] Moura DJ, Nääs IA, Pereira DF, Silva RBTR, Camargo GA. Animal welfare concepts and strategy for poultry production: a review. Braz J Poult Sci. 2006; 8: 137-147.

[26] FAWC. Farm animal welfare: Health and disease. FAWC. London. UK. http://www.defra.gov.uk/fawc/. 2012.

[27] Berg C. Health and welfare in organic poultry production. Acta Vet Scand. 2001; Suppl. 95: 37-45.

[28] Lund V. Natural living - a precondition for animal welfare in organic farming. Livest Sci. 2006; 100: 71-83.

[29] Lund V, Hemlin S, Lockeretz W. Organic livestock production as viewed by Swedish farmers and organic initiators. Agric Human Values. 2002; 19: 255-268.

[30] Hayat A, Basheer A, Zahoor I, Mahmud A. Free-range rearing system and its impact on production and consumption of poultry: A review. Sci Inter (Lahore). 2014; 26: 1297-1300.

[31] von Borell E, Sørensen JT. Organic livestock production in Europe: aims, rules and trends with special emphasis on animal health and welfare. Livest Prod Sci. 2004; 90: 3-9.

[32] Harper GC, Henson SJ. Consumer concerns about animal welfare and the impact on food choice. The Final Report. EU FAIR CT98-3678. The University of Reading, Reading, UK. 2001; Pp 3-12.

[33] Bestman MWP, Wagennar JP. Farm level factors associated with feather pecking in organic laying hens. Livest Prod Sci. 2003; 80: 133-140.

[34] Nicol CJ, Pötzsch C, Lewis K, Green LE. Matched concurrent case-control study of risk factors for feather pecking in hens on free-range commercial farms in the UK. Bri Poult Sci. 2003; 44: 515-523.

[35] Ferrante V. Welfare issues of modern laying hen farming. Ital J Anim Sci. 2009; 8 (Suppl 1): 175-189.

[36] Halvorson D, Karunakaran D, Senne D, Kelleher C, Bailey C, Abraham A, Hinshaw V, Newman J. Epizootiology of Avian Influenza - simultaneous monitoring of sentinel ducks and turkeys in Minnesota. Avian Dis. 1982; 27: 77-85.

[37] EFSA. Animal health and welfare aspects of Avian Influenza. EFSA J. 2005 $; 266: 1-12$.

[38] Thamsborg SM, Roepstorff A, Larsen M. Integrated and biological control of parasites in organic and conventional production systems. Vet Parasit. 1999; 84: 169-186.

[39] Dal Bosco A, Mugnai C, Rosati A, Paoletti A, Caporali S, Castellini C. Effect of range enrichment on performance, behavior and forage intake of free-range chickens. J Appl Poult Res. 2014; 23: 137-145. 